\title{
Antibacterial activity of silver nanoparticles activated by photodynamic therapy in infected root canals
}

\author{
Hakan Aydınn ${ }^{1, A-D}$, Kürşat Er ${ }^{1,2, A-F}$, Alper KuştarcI ${ }^{1, C, E}$, Murat Akarsu ${ }^{3, A-D}$, Gül Merve Gençer ${ }^{3, B, C}$, Hakan Er ${ }^{4,5, B-D}$, Rasih Felek ${ }^{6, B, C}$ \\ ${ }^{1}$ Department of Endodontics, Faculty of Dentistry, Akdeniz University, Antalya, Turkey \\ ${ }^{2}$ Department of Endodontics, Faculty of Dentistry, Alanya Alaaddin Keykubat University, Turkey \\ ${ }^{3}$ Department of Chemistry, Faculty of Arts and Science, Akdeniz University, Antalya, Turkey \\ ${ }^{4}$ Electron Microscopy Image Analyzing Unit, Faculty of Medicine, Akdeniz University, Antalya, Turkey \\ ${ }^{5}$ Department of Biophysics, Faculty of Medicine, Akdeniz University, Antalya, Turkey \\ ${ }^{6}$ Department of Microbiology, Faculty of Dentistry, Akdeniz University, Antalya, Turkey \\ A - research concept and design; $\mathrm{B}$ - collection and/or assembly of data; $\mathrm{C}$ - data analysis and interpretation; \\ $D$ - writing the article; $E$ - critical revision of the article; $F$ - final approval of the article
}

\section{Address for correspondence \\ Kürşat Er}

E-mail: qursater@hotmail.com

\section{Funding sources \\ The work was supported by the Scientific Research Projects Coordination Unit of Akdeniz University in Antalya, Turkey} (grant No. TDH-2015-778).

Conflict of interest

None declared

Received on March 24, 2020

Reviewed on May 3, 2020

Accepted on June 6, 2020

Published online on December 31, 2020

Cite as

Aydin H, Er K, Kuştarcı A, et al. Antibacterial activity of silver nanoparticles activated by photodynamic therapy in infected root canals. Dent Med Probl. 2020;57(4):393-400. doi:10.17219/dmp/123615

DOI

10.17219/dmp/123615

Copyright

○) 2020 by Wroclaw Medical University

This is an article distributed under the terms of the

Creative Commons Attribution 3.0 Unported License (CC BY 3.0)

(https://creativecommons.org/licenses/by/3.0/).

\begin{abstract}
Background. Root canal disinfection includes mechanical, chemical and biological struggle against microorganisms (MOs). Photodynamic therapy (PDT) and nanoparticle (NP) agents may be proposed as an alternative for use against intracanal infections due to their ability to disrupt biofilm and prevent bacterial adhesion to dentin. The use of NP agents in combination with light/photosensitizer (PS) agents increases the efficiency of PDT in root canal disinfection.

Objectives. The aim of the study was to evaluate the effect of light application - PDT - on the antibacterial activity of the combination of a PS agent (toluidine blue 0 -TBO) and an NP agent (silver nanoparticles - AgNPs) for the disinfection of the root canals inoculated with Enterococcus faecalis (E. faecalis).

Material and methods. In this study, concentrations of 20 ppm of TBO and 10 ppm of AgNPs, which showed the highest antibacterial activity against $E$. faecalis in the TBO/AgNPs combination, were used according to the preliminary studies. After instrumentation, 120 human, single-rooted, straight-canal mandibular premolars of a standard length of $13 \mathrm{~mm}$ were contaminated with bacteria, and experimental procedures were conducted against 21-day-old mature biofilm. The teeth were randomly divided into 5 main experimental groups: TBO/light; AgNPs; TBO/AgNPs; AgNPs/light; and TBO/AgNPs/light. Then, these main groups were divided into 2 subgroups each, according to the 2 application time periods ( $30 \mathrm{~s}$ and 60 s) $(n=10)$. The remaining 20 teeth constituted positive and negative control groups. The data was analyzed with the Kolmogorov-Smirnov test, one-way analysis of variance (ANOVA), Tukey's honestly significant difference (HSD) test, and the Bonferroni correction.
\end{abstract}

Results. The $\mathrm{NaOCl}$ group provided a bacterial reduction that was higher than in all other groups in a statistically significant manner. Light application on the TBO/AgNPs combination was the group that provided the highest bacterial reduction after $\mathrm{NaOCl}$.

Conclusions. The photoactivation of the TBO/AgNPs combination led to an increase in the effect of PDT, and it has the potential to be used as an adjunct for disinfection of the root canal system.

Key words: silver nanoparticles, photodynamic therapy, root canal disinfection 


\section{Introduction}

One of the main purposes of endodontic treatment is to completely eliminate microorganisms (MOs) from root canals. ${ }^{1}$ Root canal disinfection with mechanical cleaning and irrigation with antimicrobial agents is important to achieve this aim. However, according to the literature, current disinfection techniques cannot completely eliminate the microbial flora from the infected areas. ${ }^{2-4}$ To improve the antimicrobial effect, innovative delivery systems are needed.

Since photodynamic therapy (PDT) increases microbial decontamination after chemomechanical preparation, it is recommended as an adjunct for endodontic treatment. ${ }^{5-8}$ Nontoxic photosensitizer (PS) agents, such as toluidine blue $\mathrm{O}$ (TBO), and irradiation at an appropriate wavelength are used in $\mathrm{PDT}^{.9-11}$ The photosensitizer, which is activated by irradiation, reacts with molecular oxygen in order to produce highly reactive oxygen species (ROS), which lead to the damage and death of MOs. ${ }^{12}$ The photosensitizer binds to the cell membranes of the bacteria, then it leads to singlet oxygen generation as a result of irradiation, and bacterial death takes place as a result of the degradation of the bacterial wall with singlet oxygen. ${ }^{13}$

One of the subjects that researchers have recently focused on is the use of nanoparticles (NPs) for antimicrobial purposes, since endodontic treatment and novel techniques, such as PDT, cannot ensure complete success in bacterial elimination. ${ }^{14-17}$ Nanoparticles such as chitosan, ${ }^{18}$ magnesium oxide, ${ }^{19}$ zinc oxide, ${ }^{20}$ quaternary ammonium polyethylenimine, ${ }^{21}$ poly(lactic-co-glycolic acid) (PLGA), ${ }^{22}$ and silver nanoparticles (AgNPs) ${ }^{15,16}$ have been researched in order to increase the efficacy of root canal disinfection.

Silver nanoparticles have at least 1 dimension that is between 1 and $100 \mathrm{~nm}$, and the surface area-volume rate considerably increases with the decreasing particle dimension. This condition results in significant changes in physical, chemical and biological characteristics. ${ }^{23}$ Its antimicrobial effect is attributed to the strong oxidative activity of the surfaces of AgNPs and the release of $\mathrm{Ag}$ ions $\left(\mathrm{Ag}^{+}\right)$in biological environments. ${ }^{24}$ The antibacterial, antifungal, antiviral, and anti-inflammatory activity of AgNPs has recently attracted great attention in biomedical practices. ${ }^{23}$

One of the most important advantages of nanomaterials is the potential for improving drug delivery in order to provide the maximum therapeutic effect in the target area. ${ }^{25}$ Nanoparticles that are functionalized with PSs enable physicochemical advantages, such as target cell selectivity, increasing the uptake of PS in cells, reducing the leakage of PS from the target cells, and allowing the controlled release of ROS. ${ }^{14}$ Combinations such as chitosan NPs functionalized with rose bengal (RB), which is a PS agent, $^{14}$ and methylene blue (MB)-loaded PLGA NPs ${ }^{22}$ have been used for this purpose. However, to the best of our knowledge, there is no study assessing the effect of photoactivation on the combination of TBO and AgNPs in the literature.

The aim of this study was to research the amount of antibacterial activity increment achieved through light application on the combination of a PS agent - TBO and an NP agent - AgNPs on the 3-week-old mature Enterococcus faecalis (E. faecalis) biofilm formed experimentally on the extracted human teeth. The study hypothesis was that light application on the TBO and AgNPs combination does not have any additional antibacterial effect as compared to the separate usage of PDT and AgNPs.

\section{Material and methods}

Ethical approval for this study was obtained from the Research Ethics Committee of Akdeniz University in Antalya, Turkey (No. 70904504/147).

\section{Synthesis and characterization of silver nanoparticles}

A total of $0.21 \mathrm{~g}$ of highly pure silver nitrate (Merck, Kenilworth, USA) was dissolved in $20.79 \mathrm{~g}$ of distilled water, and then diluted with $44.8 \mathrm{~g}$ of distilled water. An amount of $0.68 \mathrm{~g}$ of the diluted polyvinylpyrrolidone (Sigma-Aldrich, St. Louis, USA) solution (10 wt\%, diluted with water) was added dropwise into the Ag solution. An amount of $0.1568 \mathrm{~g}$ of potassium bromide (SigmaAldrich) was dissolved in $66.52 \mathrm{~g}$ of distilled water in a separate container, and then added dropwise into the Ag-polyvinylpyrrolidone solution; the obtained mixture was stirred for $5 \mathrm{~h}$ at room temperature. This final mixture had an Ag concentration of 1,000 ppm and was used as a basis to prepare solutions in the subsequent experiments. Distilled and sterilized water was used to dilute the main 1,000 ppm AgNPs solution.

\section{Preliminary studies}

Toluidine blue $\mathrm{O}, \mathrm{AgNPs}$ and their combination were used in the operation of the experimentally infected root canals of the extracted teeth. Before the experiment, preliminary studies were performed in order to determine which concentration produced the optimum effect of the photoactivation of each combination. Antibacterial efficacy was tested on a planktonic E. faecalis culture (ATCC 29212). Primarily, in order to determine to what extent NPs were superior to $\mathrm{Ag}^{+}, 10 \mathrm{ppm}$ of the $\mathrm{Ag}^{+}$-containing silver nitrate solution (in distilled water) and $10 \mathrm{ppm}$ of the AgNPs solution were prepared, and efficacy tests were done. It was found that when PDT was not applied to the samples with a bacterial density of $1 \times 10^{4} \mathrm{CFU} / \mathrm{mL}$, the antibacterial activity of AgNPs was about 6\% lower 
than that of $\mathrm{Ag}^{+}$and, on the contrary, when PDT was applied with a 30-second duration, the activity of AgNPs was about $20 \%$ higher than in the case of $\mathrm{Ag}^{+}$.

Subsequently, the TBO/AgNPs rates to be used with PDT were studied. When the concentration of AgNPs in the $20 \mathrm{ppm}$ TBO solution was increased from $5 \mathrm{ppm}$ to $10 \mathrm{ppm}$, a reduction in the bacterial load rose from $99.7 \%$ to $99.9 \%$. On the other hand, when the concentration of AgNPs was increased to $20 \mathrm{ppm}$, a reduction in the bacterial load fell to $91 \%$. As expected, in the control samples there was not any reduction. In preliminary trials, due to the highest amount of reduction being achieved with $20 \mathrm{ppm}$ TBO + $10 \mathrm{ppm}$ AgNPs, it was decided to continue further studies with this TBO/AgNPs rate.

\section{Selection and preparation of tooth samples}

One hundred and thirty mature mandibular premolars with straight root canals, extracted for periodontal and/or prosthetic reasons, were obtained with written informed consent. Digital radiographs were taken from mesiodistal and buccolingual directions in order to check if the teeth had the desired anatomic structures, and it was confirmed that they had single canals. The teeth were stored in the thymol solution until required.

The crowns of the teeth were removed under water with a low-speed diamond saw (Komet USA, Rock Hill, USA) to obtain a root height of $13 \mathrm{~mm}$. This standard length allowed root canal shaping and disinfection strategies to be performed under similar conditions for all samples. A K-file size 10 (Micro-Mega, Besançon, France) was inserted into the root canal until the tip of the file was visible at the apical foramen, and the working length (WL) was determined by subtracting $1 \mathrm{~mm}$ from this length. The preparation of root canals was performed with the ProTaper ${ }^{\circledR}$ Universal nickel-titanium rotary files (Dentsply Maillefer, Ballaigues, Switzerland) in accordance with the manufacturer's instructions, using the crown-down preparation technique. Files SX, S1, S2, F1, F2, F3, and F4 were used respectively according to the recommended speed and torque adjustments. Root canal shaping was completed when the master apical file was F4. During shaping, root canals were irrigated with $2.5 \mathrm{~mL}$ of $2.5 \% \mathrm{NaOCl}$ after each file change, using a standard dental needle with a 27-gauge tip. Final irrigation was performed using $5 \mathrm{~mL}$ of $17 \%$ EDTA solution (Calasept EDTA; Nordiska Dental, Ängelholm, Sweden) for $2 \mathrm{~min}, 2 \mathrm{~mL}$ of $2.5 \% \mathrm{NaOCl}$ and $5 \mathrm{~mL}$ of saline. The teeth were maintained in saline for 5 days to eliminate residual $\mathrm{NaOCl}$. Root canals were dried with the ProTaper F4 paper points (Dentsply Maillefer). The apical foramina of the teeth were sealed with light-polymerized flowable composite resin (CLEARFIL MAJESTYTM Flow; Kuraray Noritake Dental Inc., Okayama, Japan) in order to prevent bacterial leakage and irrigant overflow. Two layers of nail polish were rigorously applied on the root surfaces of the teeth. Then, the samples were sterilized in ethylene oxide. After sterilization, 5 samples were randomly selected in order to confirm the complete elimination of bacteria and the removal of smear layers with scanning electron microscopy (SEM).

\section{Cultivation of Enterococcus faecalis and root canal contamination}

All microbiological procedures in this study were conducted under aseptic conditions and in a laminar flow cabinet. An E. faecalis strain (ATCC 29212) was used as the test bacteria in the study. The E. faecalis were taken from frozen stocks. The cultures were maintained by being subcultured in broth that contained trypticase soy agar, and the strain was inoculated in blood agar. The cultures were prepared by being incubated for $24 \mathrm{~h}$ at $37^{\circ} \mathrm{C}$ in a micro-aerofilic environment. The number of cells was adjusted in a spectrometer device (the Cary 5000 Bio UV-Vis spectrophotometer; Varian Medical Systems, Palo Alto, USA) according to their optical density so that $10^{8}$ cells in every $\mathrm{mL}$ of the broth were included. These measurements were performed at a wavelength of $600 \mathrm{~nm}$.

Each one of the 125 teeth was transferred to sterile 1.5-milliliter Eppendorf tubes. Following the injection of $1 \mathrm{~mL}$ of the brain-heart infusion (BHI) broth (Merck), containing $10^{8}$ E. faecalis cells, to the prepared root canals with insulin injectors, each sample was entirely submerged in the BHI broth. ${ }^{26}$ It was incubated for the formation of the E. faecalis biofilm in an incubator at $37^{\circ} \mathrm{C}$ for 21 days. The broth in each tube was refreshed every day. Following the incubation period, the mediums in the tubes were aseptically aspirated and the residual mediums were eliminated from root canals by means of paper points.

\section{Photosensitizer and a light source}

A light-emitting diode (LED) device (FotoSan ${ }^{\circledR}$; CMS Dental, Copenhagen, Denmark) was used as a light source in the experimental procedures. The output power of the system was $2,000-4,000 \mathrm{~mW} / \mathrm{cm}^{2}$, and its wavelength spectrum was between 620 and $640 \mathrm{~nm}$. Although there was TBO at a concentration of $0.1 \mathrm{mg} / \mathrm{mL}$ as a PS agent in the system, $0.02 \mathrm{mg} / \mathrm{mL}$ of TBO was used according to the aforementioned preliminary study results. The endodontic tip was introduced as deeply as possible into the root canal without applying pressure.

\section{SEM preparation and analysis}

Five samples were analyzed with SEM (the Zeiss Leo 1430 scanning electron microscope; Carl Zeiss, Oberkochen, Germany) in order to verify the formation of the E. faecalis biofilm. Five random teeth were selected from among the samples. Longitudinal grooves 
were carved on the root surfaces without invading the inner part of the root canal with a high-speed diamond bur (Komet USA). Afterward, the roots were divided into 2 parts through these grooves with the help of a stainless steel chisel. The samples were irrigated with saline in order to remove cells that were not bound to the biofilm. The samples were fixed in $10 \%$ formalin for $24 \mathrm{~h}$, then incubated for $20 \mathrm{~min}$ in a graded series of ethanol concentrations (50\%, 70\%, 90\%, and 100\%, twice) and left to dry in the air at room temperature during the night. Later, they were mounted on the aluminum stubs of the scanning electron microscope, sputter coated with a 300-angstrom gold-palladium alloy under vacuum and analyzed at $15 \mathrm{kV}$. The SEM images of the apical, middle and coronal thirds and fracture surfaces were taken.

\section{Experimental procedures}

The remaining 120 teeth were randomly divided into 5 main experimental groups $(n=20)$. Then, these main groups were divided into 2 subgroups $(n=10)$. In total, there were 10 experimental groups:

- group 1A: TBO at a concentration of $0.02 \mathrm{mg} / \mathrm{mL}$ $(20 \mathrm{ppm})$ was injected into root canals and agitated with a K-file size 15; it was left in root canals for $1 \mathrm{~min}$, and then activated for $30 \mathrm{~s}$ with the help of the 0.5 -millimeter tip of the FotoSan light delivery system;

- group 1B: the same procedures as in group 1A were applied, but following a 30-second break, another $30 \mathrm{~s}$ of light application was performed; photoactivation was performed for a total of $60 \mathrm{~s}$;

- group 2A: AgNPs at a concentration of $10 \mathrm{ppm}$ were injected into root canals and left for $30 \mathrm{~s}$ after being agitated with a hand file size 15;

- group 2B: AgNPs at a concentration of 10 ppm were injected into the root canals and left for $60 \mathrm{~s}$ after being agitated with a hand file size 15 ;

- group 3A: the homogeneous distribution of the mixture of 20 ppm of TBO and 10 ppm of AgNPs was ensured; later, this was placed into root canals and kept for $30 \mathrm{~s}$;

- group 3B: the same procedures as in group 3A were applied, but for $60 \mathrm{~s}$;

- group 4A: AgNPs at a concentration of $10 \mathrm{ppm}$ were injected into root canals and photoactivation was performed for $30 \mathrm{~s}$;

- group 4B: AgNPs at a concentration of $10 \mathrm{ppm}$ were injected into root canals and photoactivation was performed for $60 \mathrm{~s}$;

- group 5A: the mixture of $20 \mathrm{ppm}$ of TBO and $10 \mathrm{ppm}$ of AgNPs was injected into root canals; it was kept for $1 \mathrm{~min}$ for its distribution into the root canal system, and then photoactivation was performed for $30 \mathrm{~s}$;

- group 5B: the mixture of $20 \mathrm{ppm}$ of TBO and $10 \mathrm{ppm}$ of AgNPs was injected into root canals; it was kept for $1 \mathrm{~min}$ for its distribution into the root canal system, and then photoactivation was performed for $60 \mathrm{~s}$.
The remaining 20 teeth constituted positive and negative control groups. The samples were irrigated with $2 \mathrm{~mL}$ of $2.5 \% \mathrm{NaOCl}$ for $1 \mathrm{~min}$ in the positive control group $(n=10)$. The teeth in the positive control group were irrigated with $5 \mathrm{~mL}$ of $5 \%$ sodium thiosulphate for $1 \mathrm{~min}$ in order to inactivate the $\mathrm{NaOCl}$ remaining in the canal. ${ }^{26}$ The samples were irrigated with $2 \mathrm{~mL}$ of $0.9 \%$ saline solution for $1 \mathrm{~min}$ in the negative control group $(n=10)$.

\section{Microbiological analysis}

The microbiological analysis was conducted in all experimental and control groups before and just after the treatment regimens. After the treatment regimens, root canals were irrigated with $1 \mathrm{~mL}$ of saline in order to remove the agents. As in the method used by Souza et al., ${ }^{27}$ root canals were filled with saline in the sampling procedures and samples were taken with 3 sterile paper points in order. These paper points were combined to count CFU. Paper points were introduced up to WL in root canals for $1 \mathrm{~min}$. Before placing paper points for the microbiological sampling following the treatment, root canals were filed vigorously with an $\mathrm{H}$-file size $25 .{ }^{11}$ This procedure allowed the biofilm to deteriorate and the bacteria which were left in the biofilm and could not be reached with paper points to be obtained. The bacterial CFU were counted and the actual counts were determined based on the known dilution factors.

\section{Statistical analysis}

The statistical analyses of the results were carried out using IBM SPSS Statistics for Windows, v. 20.0 (IBM Corp., Armonk, USA). The reduction percentages in the data obtained by counting CFU after the treatment were transformed into logarithmic $\left(\log _{10}\right)$ values. The Kolmogorov-Smirnov test, the one-way analysis of variance (ANOVA) and Tukey's honestly significant difference (HSD) test were used to carry out the statistical analyses of the study data. After the Bonferroni correction, $p<0.004$ was taken as the level of statistical significance.

\section{Results}

\section{Characterization of nanoparticles}

The dimension distributions of the synthesized AgNPs were measured using the Nano-Z device of the Zetasizer ${ }^{\circledR}$ Nano series (Malvern Panalytical, Malvern, UK), which operates based on the principle of dynamic light scattering. The average size of the particles which were synthesized according to the measurements was $52 \mathrm{~nm}$. The effect of the synthesized AgNPs on TBO absorption was analyzed using ultraviolet-visible (UV-Vis) spectroscopy. When the UV-Vis spectra of the 20 ppm of TBO, 
$20 \mathrm{ppm}$ of TBO + 10 ppm of AgNPs and 10 ppm of AgNPs solutions were examined, it was observed that only the solution containing AgNPs did not lead to any absorption in the visible area. On the other hand, TBO led to a maximum absorption of approx. $600 \mathrm{~nm}$. The addition of AgNPs to the TBO solution did not change this maximum absorption.

\section{SEM analysis}

The SEM images which were examined to verify the complete elimination of smear layers and bacteria before the canal systems were contaminated with E. faecalis, following the preparation of the root samples, showed clean dentin surfaces with open dentinal tubules (Fig. 1).
The SEM images verified the presence of 21-day-old mature biofilm before the treatment protocols were performed (Fig. 2). The root canal walls were densely colonized by E. faecalis cells. In some areas, the cells were organized in biofilm and observed to have penetrated dentinal tubules.

\section{Bacteriological analysis}

Table 1 illustrates average reduction percentages and average reduction amounts as logarithmic values after the treatment in all groups. The initial and post-treatment average $\mathrm{NaOCl}$ group provided a bacterial reduction that was higher than in all other groups in a statistically significant manner; it was the group which displayed the highest

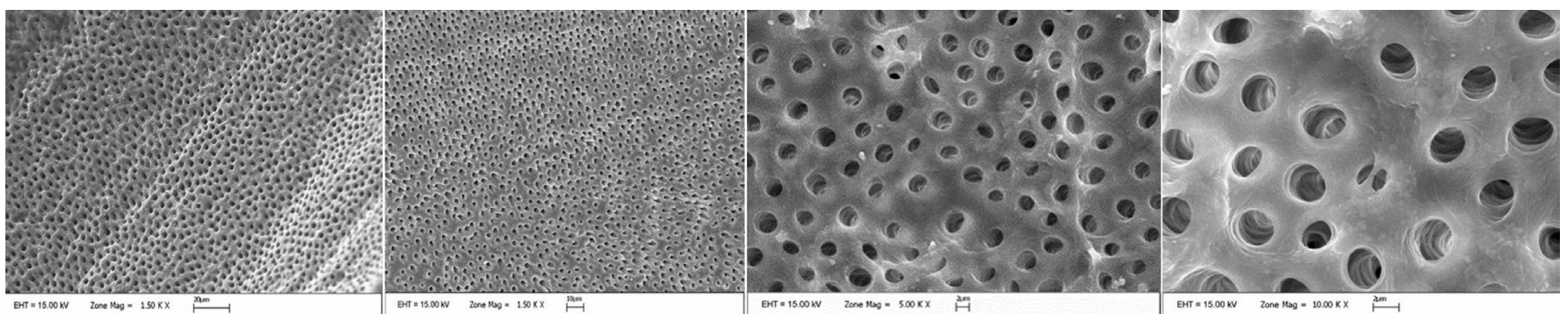

Fig. 1. Clean dentinal tubules with no smear layers
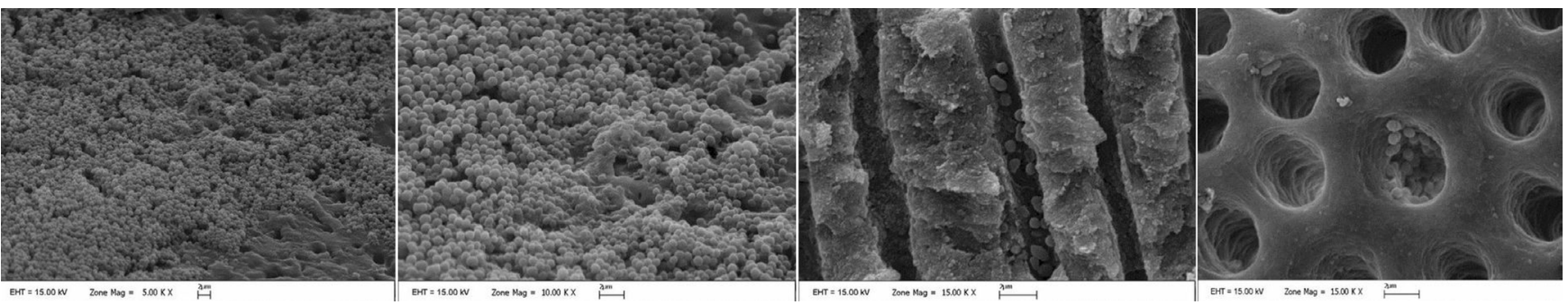

Fig. 2. Root canal walls heavily colonized with bacteria; bacterial cells observed in dentinal tubules

Table 1. Average logarithmic and percentage values of bacterial reduction in all groups

\begin{tabular}{|c|c|c|c|c|c|}
\hline Groups & $n$ & $\begin{array}{l}M \pm S D \\
{\left[\log _{10}\right]}\end{array}$ & Range & $\begin{array}{c}M \pm S D \\
{[\%]}\end{array}$ & Range \\
\hline TBO/light $30 \mathrm{~s}^{\mathrm{a}-\mathrm{j}, \mathrm{k}}$ & 10 & $1.63 \pm 0.23$ & $1.23-1.97$ & $97.34 \pm 1.56$ & $94.13-98.92$ \\
\hline TBO/light $60 \mathrm{~s}^{\mathrm{b}-\mathrm{k}, \mathrm{m}}$ & 10 & $2.03 \pm 0.19$ & $1.64-2.29$ & $98.98 \pm 0.51$ & $97.72-99.49$ \\
\hline AgNPs $30 s^{c-j, k}$ & 10 & $1.61 \pm 0.43$ & $1.24-2.71$ & $96.80 \pm 1.84$ & $94.20-99.80$ \\
\hline AgNPs $60 s^{d-k, m}$ & 10 & $1.95 \pm 0.29$ & $1.52-2.38$ & $98.65 \pm 0.88$ & $97.00-99.58$ \\
\hline TBO/AgNPs $30 s^{e-j, k}$ & 10 & $1.80 \pm 0.58$ & $1.11-2.94$ & $97.28 \pm 2.35$ & $92.15-99.88$ \\
\hline TBO/AgNPs $60 s^{f-k, m}$ & 10 & $1.93 \pm 0.55$ & $0.83-2.80$ & $97.36 \pm 4.40$ & $85.31-99.84$ \\
\hline AgNPs/light $30 s^{g-j, k}$ & 10 & $1.84 \pm 0.19$ & $1.51-2.13$ & $98.41 \pm 0.73$ & $96.94-99.26$ \\
\hline AgNPs/light $60 \mathrm{~s}^{\mathrm{h}-\mathrm{k}, \mathrm{m}}$ & 10 & $2.10 \pm 0.31$ & $1.55-2.49$ & $98.96 \pm 0.90$ & $97.16-99.68$ \\
\hline TBO/AgNPs/light $30 \mathrm{~s}^{i-k, m}$ & 10 & $2.14 \pm 0.26$ & $1.89-2.80$ & $99.18 \pm 0.34$ & $98.71-99.84$ \\
\hline TBO/AgNPs/light $60 s^{j-a, c, e, g, k, m}$ & 10 & $2.71 \pm 0.60$ & $1.74-3.85$ & $99.61 \pm 0.52$ & $98.18-99.99$ \\
\hline Positive controlk-a,b,c,d,e,f,g,h,h,i,j,m & 10 & $4.29 \pm 0.96$ & $2.95-6.00$ & $99.98 \pm 0.03$ & 99.89-100.00 \\
\hline Negative controlm-b,d,f,h,i,j,k & 10 & $1.02 \pm 0.20$ & $0.71-1.40$ & $89.70 \pm 4.49$ & $80.63-96.05$ \\
\hline
\end{tabular}

TBO - toluidine blue O; AgNPs - silver nanoparticles; M - mean; SD - standard deviation; a TBO/light 30 s; ${ }^{b}$ TBO/light 60 s; ${ }^{c}$ AgNPs 30 s; ${ }^{\text {d }}$ AgNPs 60 s; e TBO/AgNPs $30 \mathrm{~s} ;{ }^{\mathrm{f}} \mathrm{TBO} / \mathrm{AgNPs} 60 \mathrm{~s} ;{ }^{9}$ AgNPs/light $30 \mathrm{~s} ;{ }^{\text {h }}$ AgNPs/light $60 \mathrm{~s} ;{ }^{i}$ TBO/AgNPs/light $30 \mathrm{~s} ;{ }^{j}$ TBO/AgNPs/light $60 \mathrm{~s} ;{ }^{k}$ positive control; ${ }^{2}$ negative control. Superscript letters show significant differences between the related group and the other groups. 
antibacterial activity. Increasing the treatment time from $30 \mathrm{~s}$ to $60 \mathrm{~s}$ caused an increase in antibacterial activity; however, it was not statistically significant. The saline group was the least successful one; yet, no significant difference was found between groups $1 \mathrm{~A}, 2 \mathrm{~A}, 3 \mathrm{~A}$, and $4 \mathrm{~A}$. Light application on the TBO/AgNPs combination was the group that provided the highest bacterial reduction after $\mathrm{NaOCl}$.

\section{Discussion}

The present study analyzed the antibacterial activity obtained by light application on the combination of a PS agent - TBO and an NP agent - AgNPs on the 3-weekold mature E. faecalis biofilm formed experimentally on the extracted human teeth, and compared it to the same combination without photoactivation, light application on TBO, the separate use of AgNPs, and light application on AgNPs. The teeth treated with saline and $\mathrm{NaOCl}$ served as control groups.

The study consisted of 2 stages. At the $1^{\text {st }}$ stage, a preliminary study was conducted to establish at which concentrations the procedures of combining TBO and AgNPs as well as applyinglight on this combination showed the best results. It was observed that the combination of $20 \mathrm{ppm}$ of TBO and 10 ppm of AgNPs showed the most effective antibacterial activity against the suspension containing E. faecalis. Hence, these concentrations were used in the experiment conducted on the prepared root samples. In the analysis of the UV-Vis spectra, it was noted that the solution containing AgNPs did not lead to absorption and TBO resulted in absorption at approx. $600 \mathrm{~nm}$. The addition of AgNPs to the TBO solution did not change the maximum absorption. Based on these results, the FotoSan device, which provided light at a wavelength of approx. $600 \mathrm{~nm}$, was preferred as the source of light to be used in the experiment.

Enterococcus faecalis was used in this study, as it is generally believed that these bacteria are one of the most common isolated MOs found in infected root canals and has a higher prevalence in secondary infections as compared to primary infections. ${ }^{28}$ Despite having various virulence factors, their capability of causing periradicular diseases arises from being persistant and protected from the effects of the root canal treatment procedures, applied in the root canals and dentinal tubules of the tooth. ${ }^{29}$ In addition, MOs in biofilm have a stronger pathogenic potential as compared to planktonic MOs. ${ }^{30,31}$ Clinically, they are of particular importance due to their higher capability of protecting themselves from host defense mechanisms and therapeutic approaches, such as chemical and mechanical antimicrobial treatment procedures. ${ }^{32}$ The presence of mature biofilm was detected in the SEM images taken before performing the treatment regimens. This provided for the method of the infected dentin model to be used; colonization was present in the canal lumens and dentinal tubules, the possible relationship between the applied agents and dentin was taken into consideration, the effects related to the penetration and distribution of agents in a closed environment, such as the root canal system, were taken into consideration, a dark environment was provided during light application, and the administration and duration of agents were similar to those met in clinical conditions. Thus, the conditions closest to the clinical ones were obtained.

$\mathrm{NaOCl}$ is suggested as the primary irrigation solution in endodontics due to its wide-spectrum antimicrobial efficiency as well as its capability of dissolving organic substances. ${ }^{33}$ Photodynamic therapy is antimicrobial treatment on which numerous studies have been conducted ${ }^{7,34-36}$ and the efficiency of which has been proven in endodontics. Eliminating the bacteria selectively without affecting other normal tissue and damaging surrounding tissues is among its advantages. ${ }^{37}$ In studies conducted on PDT, some researchers have found PDT to be more successful than $\mathrm{NaOCl}^{11,38}$ or as efficient as $\mathrm{NaOCl},{ }^{39}$ while others found it to be less successful and reported contradictory results. ${ }^{40,41}$ The reason for these reported differences is associated with the methodologies used, $\mathrm{NaOCl}$ concentrations and the diversity of PDT procedures. Hecker et al. asserted that PDT was ineffective in ensuring sufficient disinfection. ${ }^{34}$

It is difficult to make comparisons between studies conducted on the efficiency of PDT. This is because different PSs, PS concentrations, light parameters, irradiation durations, and light delivery systems were used. In this study, the $\mathrm{NaOCl}$ group displayed statistically significantly higher antibacterial efficiency as compared to PDT and the other groups. Despite a significant decrease in the number of bacteria, complete elimination was not achieved with PDT. In their study conducted on teeth with pulpal necrosis and periapical pathology, Ng et al. applied PDT after the chemomechanical cleaning of canals and found that the bacterial load decreased with PDT. ${ }^{42}$ However, they construed that the failure to obtain complete elimination was associated with the incomplete penetration of PS into dentinal tubules due to bonding through the interaction of PS with dentin components, the failure of the penetration of PS into the canal biofilm and the insufficient amount of oxygen. ${ }^{42}$

In a micro-environment with low oxygen levels, such as the closed environment surrounded by dentinal tubules, molecular oxygen is quickly depleted, and singlet oxygenmediated damage is prevented or minimized. It is recommended to fractionate light delivery and apply irradiation once again after some time in order to overcome the problem of oxygen consumption. ${ }^{43}$ In the current study, the application of PDT was performed once again after $30 \mathrm{~s}$. The efficacy of PDT increased, although the rise was not statistically significant.

Silver nanoparticles have attracted a great deal of attention in biomedical applications recently, since they show antibacterial, antifungal, antiviral, and anti-inflammatory activity. ${ }^{23}$ They lead to apoptosis and necrosis by stimulating potent oxidative damage to organelles such as the cell 
membrane, lysosome, mitochondrium, and nucleus. ${ }^{44}$ Biological cellular proteins are negatively charged due to their side chains, which may contain carboxyl and sulfhydryl groups, and the high affinity of Ag for negatively charged molecules in the cells of bacteria inactivates the critical functions of bacterial cells, and prevents bacterial growth and biofilm formation. ${ }^{45}$ Therefore, positively charged NPs have more antibacterial effects than negatively charged and neutral NPs. ${ }^{17}$

Abbaszadegan et al. evaluated the antibacterial activity and cytotoxicity of stable AgNPs synthesized with different surface charges (neutral, positive and negative), and compared them with the $\mathrm{NaOCl}$ and chlorhexidine ( $\mathrm{CHX}$ ) solutions. ${ }^{17}$ Silver nanoparticles with a positive surface charge were effective at considerably low concentrations as compared to other agents. ${ }^{17}$ Similarly, Lotfi et al. demonstrated that AgNPs could have the same bactericidal effect as $5.25 \% \mathrm{NaOCl}$ at considerably low concentrations. ${ }^{46}$ In their study, 70 times higher $\mathrm{NaOCl}$ concentration was required to obtain the equivalent antibacterial effect of AgNPs. ${ }^{46}$ Contrary to the results of these studies, Wu et al. compared the antibacterial effect of the 0.1\% AgNPs solution with $2 \% \mathrm{NaOCl}$ and saline in dentin samples. ${ }^{15}$ In the study in which they evaluated the residual biofilm structure with SEM and confocal laser scanning microscopy (CLSM), irrigation was performed for 2 min with $6 \mathrm{~mL}$ of the solutions. The $0.1 \%$ AgNPs solution did not disrupt the structure of the E. faecalis biofilm, but provided a significant biofilm bacteria death. $\mathrm{NaOCl}$ was found to be more successful than the other groups. ${ }^{15}$ The results of this study are similar to ours. However, our study was aimed at improving disinfection before canal filling, with the AgNPs solution not as an irrigation solution. Therefore, our study enabled a comparison with the PDT group, and displayed similar antibacterial efficiency of AgNPs and PDT.

One of the most important advantages of nanomaterials is the potential for improving drug delivery in order to ensure the maximum therapeutic effect in the target area. ${ }^{25}$ However, in PDT, PSs have insufficient water solubility and tend to cluster in an aqueous environment under physiological conditions ${ }^{47}$ In order to overcome this problem, an advanced non-invasive light-activated disinfection procedure that consists of 2 stages has been suggested; the $1^{\text {st }}$ stage consists in using PS that is dissolved in a formulation, which increases its photochemical characteristics and allows a better diffusion of PS to the anatomical complexities of the root canal system. Then, the $2^{\text {nd }}$ stage facilitates light distribution in the irradiation phase and an oxygen-carrying solution is applied, which increases the amount of oxygen. ${ }^{48}$ Another method is to increase the solubility of hydrophobic PS through the use of NP agents as carriers in drug delivery in order to improve the transfer of PS to the target tissue. ${ }^{47}$ Nanoparticles that are functionalized with PSs enable physicochemical advantages, such as target cell selectivity, increasing the uptake of PS in cells, reducing the leakage of PS from the target cells, increasing the stability of PS molecules after conjugation, preventing the physical quenching caused by PS aggression, and allowing the controlled release of ROS. ${ }^{14}$

In a study using chitosan NPs functionalized with RB, which is a xanthen PS dye, antibiofilm efficiency in the multiple-species biofilm formed in dentin was investigated, and increased affinity to bacterial cell membrane, more penetration into the biofilm structure and more bacterial elimination were obtained. ${ }^{14}$ Shrestha and Kishen evaluated the antibacterial efficiency of this conjugation in the presence of tissue inhibitors in root canals. ${ }^{49}$ The synergistic antibacterial effect of chitosan NPs and singlet oxygen released from $\mathrm{RB}$ after photoactivation ensured a significant antibacterial efficiency potential for this conjugation, even in the presence of tissue inhibitors. ${ }^{49}$ Pagonis et al. examined the antibacterial efficiency of MB-loaded PLGA NPs and their photoactivation against E. faecalis. ${ }^{22}$ After keeping the solution in the canal for $15 \mathrm{~min}$, irradiation was performed with the help of a diode laser for $5 \mathrm{~min}$. After irradiation, a significant decrease in the CFU values was found. ${ }^{22}$ In the present study, antibacterial efficiency was increased by means of light application on the TBO and AgNPs combination, and this was the most successful group after $\mathrm{NaOCl}$. Thus, the null hypothesis was rejected.

This study has several limitations. Firstly, to the best of our knowledge, there is still no information in the literature concerning the photoactivation of the combination of TBO and AgNPs. Therefore, making a comparison is not possible. Secondly, only 1 bacterial strain was evaluated, while endodontic infections are polymicrobial. Thirdly, various possible light sources and wavelength ranges can change the antimicrobial effects of PSs or AgNPs. Currently, there is a lack of an established protocol for adjunctive PDT for root canal disinfection.

\section{Conclusions}

All the treatment protocols used in this study displayed strong antibacterial efficiency on mature E. faecalis biofilm. The photoactivation of the TBO/AgNPs combination led to an increase in the effect of PDT, and only the $2.5 \%$ $\mathrm{NaOCl}$ group was more effective. The use of NP agents in combination with light/PS agents plays an important role in increasing the efficiency of PDT in root canal disinfection It is required for future studies to research the effect of this combination on multiple-species biofilm, its cytotoxicity and its efficacy in the presence of tissue inhibitors.

\section{ORCID iDs}

Hakan Aydın (D) https://orcid.org/0000-0003-3597-0843 Kürşat Er (i) https://orcid.org/0000-0002-0667-4909

Alper Kuştarcı (i) https://orcid.org/0000-0002-4942-3739

Murat Akarsu (D) https://orcid.org/0000-0002-2114-7904

Gül Merve Gençer (D) https://orcid.org/0000-0001-7087-609X

Hakan Er (D) https://orcid.org/0000-0001-7739-4712

Rasih Felek (D) https://orcid.org/0000-0002-5722-1176 


\section{References}

1. Nair PNR. Pathogenesis of apical periodontitis and the causes of endodontic failures. Crit Rev Oral Biol Med. 2004;15(6):348-381. doi:10.1177/154411130401500604

2. Siqueira JF Jr., de Uzeda M. Disinfection by calcium hydroxide pastes of dentinal tubules infected with two obligate and one facultative anaerobic bac teria. J Endod. 1996;22(12):674-676. doi:10.1016/S0099-2399(96)80062-8

3. Siqueira JF Jr., Magalhães KM, Rôças IN. Bacterial reduction in infected root canals treated with $2.5 \% \mathrm{NaOCl}$ as an irrigant and calcium hydroxide/camphorated paramonochlorophenol paste as an intracanal dressing. J Endod. 2007;33(6):667-672. doi:10.1016/j.joen.2007.01.004

4. Siqueira JF Jr., Rôças IN, Paiva SSM, Guimarães-Pinto T, Magalhães KM, Lima KC. Bacteriologic investigation of the effects of sodium hypochlorite and chlorhexidine during the endodontic treatment of teeth with apical periodontitis. Oral Surg Oral Med Oral Pathol Oral Radiol Endod. 2007;104(1):122-130. doi:10.1016/j.tripleo.2007.01.027

5. Soukos NS, Chen PSY, Morris JT, et al. Photodynamic therapy for endodontic disinfection. J Endod. 2006;32(10):979-984. doi:10.1016/j.joen.2006.04.007

6. Garcez AS, Ribeiro MS, Tegos GP, Núñez SC, Jorge AOC, Hamblin MR. Antimicrobial photodynamic therapy combined with conventional endodontic treatment to eliminate root canal biofilm infection. Lasers Surg Med. 2007;39(1):59-66. doi:10.1002/Ism.20415

7. Fimple JL, Fontana $C R$, Foschi F, et al. Photodynamic treatment of endodontic polymicrobial infection in vitro. J Endod. 2008;34(6):728-734. doi:10.1016/j.joen.2008.03.011

8. Garcez AS, Nuñez SC, Hamblim MR, Suzuki H, Ribeiro MS. Photodynamic therapy associated with conventional endodontic treatment in patients with antibiotic-resistant microflora: A preliminary report. $J$ Endod. 2010;36(9):1463-1466. doi:10.1016/j.joen.2010.06.001

9. Benov L. Photodynamic therapy: Current status and future directions. Med Princ Pract. 2015;24 Suppl 1(Suppl 1):14-28. doi:10.1159/000362416

10. Williams JA, Pearson GJ, Colles MJ. Antibacterial action of photoactivated disinfection (PAD) used on endodontic bacteria in planktonic suspension and in artificial and human root canals. J Dent. 2006;34(6):363371. doi:10.1016/j.jdent.2005.08.002

11. Bago I, Plečko V, Gabrić Pandurić D, Schauperl Z, Baraba A, Anić I. Antimicrobial efficacy of a high-power diode laser, photo-activated disinfection, conventional and sonic activated irrigation during root canal treatment. Int Endod J. 2013;46(4):339-347. doi:10.1111/j.1365-2591.2012.02120.x

12. Demidova TN, Hamblin MR. Photodynamic therapy targeted to pathogens. Int J Immunopathol Pharmacol. 2004;17(3):245-254. doi:10.1177/039463200401700304

13. Komine C, Tsujimoto Y. A small amount of singlet oxygen generated via excited methylene blue by photodynamic therapy induces the sterilization of Enterococcus faecalis. J Endod. 2013;39(3):411-414. doi:10.1016/j.joen.2012.11.051

14. Shrestha A, Kishen A. Antibacterial efficacy of photosensitizer functionalized biopolymeric nanoparticles in the presence of tissue inhibitors in root canal. J Endod. 2014;40(4):566-570. doi:10.1016/j.joen.2013.09.013

15. Wu D, Fan W, Kishen A, Gutmann JL, Fan B. Evaluation of the antibacterial efficacy of silver nanoparticles against Enterococcus faecalis biofilm. J Endod. 2014;40(2):285-290. doi:10.1016/j.joen.2013.08.022

16. Javidi M, Afkhami F, Zarei M, Ghazvini K, Rajabi O. Efficacy of a combined nanoparticulate/calcium hydroxide root canal medication on elimination of Enterococcus faecalis. Aust Endod J. 2014;40(2):61-65. doi:10.1111/aej.12028

17. Abbaszadegan A, Nabavizadeh M, Gholami A, et al. Positively charged imidazolium-based ionic liquid-protected silver nanoparticles: A promising disinfectant in root canal treatment. Int Endod J. 2015:48(8):790800. doi:10.1111/iej.12377

18. Kishen A, Shi Z, Shrestha A, Neoh KG. An investigation on the antibacterial and antibiofilm efficacy of cationic nanoparticulates for root canal disinfection. J Endod. 2008;34(12):1515-1520. doi:10.1016/j.joen.2008.08.035

19. Monzavi A, Eshraghi S, Hashemian R, Momen-Heravi F. In vitro and ex vivo antimicrobial efficacy of nano-MgO in the elimination of endodontic pathogens. Clin Oral Investig. 2015;19(2):349-356. doi:10.1007/ s00784-014-1253-y

20. Shrestha A, Shi Z, Neoh KG, Kishen A. Nanoparticulates for antibiofilm treatment and effect of aging on its antibacterial activity. J Endod. 2010;36(6):1030-1035. doi:10.1016/j.joen.2010.02.008

21. Kesler Shvero D, Abramovitz I, Zaltsman N, Perez Davidi M, Weiss El, Beyth $\mathrm{N}$. Towards antibacterial endodontic sealers using quaternary ammonium nanoparticles. Int Endod J. 2013;46(8):747-754. doi:10.1111/iej.12054

22. Pagonis TC, Chen J, Fontana CR, et al. Nanoparticle-based endodontic antimicrobial photodynamic therapy. J Endod. 2010;36(2):322-328. doi:10.1016/j.joen.2009.10.011

23. Ge L, Li Q, Wang M, Ouyang J, Li X, Xing MMQ. Nanosilver particles in medical applications: Synthesis, performance, and toxicity. Int J Nanomedicine. 2014;9:2399-2407. doi:10.2147/IJN.S55015

24. He W, Zhou YT, Wamer WG, Boudreau MD, Yin JJ. Mechanisms of the pH dependent generation of hydroxyl radicals and oxygen induced by $\mathrm{Ag}$ nanoparticles. Biomaterials. 2012;33(30):7547-7555. doi:10.1016/j.biomaterials.2012.06.076
25. Paszko E, Ehrhardt C, Senge MO, Kelleher DP, Reynolds JV. Nanodrug applications in photodynamic therapy. Photodiagnosis Photodyn Ther. 2011;8(1):14-29. doi:10.1016/j.pdpdt.2010.12.001

26. Christo JE, Zilm PS, Sullivan T, Cathro PR. Efficacy of low concentrations of sodium hypochlorite and low-powered Er,Cr:YSGG laser activated irrigation against an Enterococcus faecalis biofilm. Int Endod J. 2016;49(3):279-286. doi:10.1111/iej.12447

27. Souza LC, Brito PRR, Machado de Oliveira JC, et al. Photodynamic therapy with two different photosensitizers as a supplement to instrumentation/ irrigation procedures in promoting intracanal reduction of Enterococcus faecalis. J Endod. 2010;36(2):292-296. doi:10.1016/j.joen.2009.09.041

28. Pinheiro ET, Gomes BPFA, Ferraz CCR, Sousa ELR, Teixeira FB, Souza-Filho FJ. Microorganisms from canals of root-filled teeth with periapical lesions. Int Endod J. 2003;36(1):1-11. doi:10.1046/j.1365-2591.2003.00603.x

29. Stuart CH, Schwartz SA, Beeson TJ, Owatz CB. Enterococcus faecalis: Its role in root canal treatment failure and current concepts in retreatment. J Endod. 2006;32(2):93-98. doi:10.1016/j.joen.2005.10.049

30. Lewis K. Riddle of biofilm resistance. Antimicrob Agents Chemother. 2001;45(4):999-1007. doi:10.1128/AAC.45.4.999-1007.2001

31. Chałas R, Wójcik-Chęcińska I, Woźniak MJ, Grzonka J, Święszkowski W, Kurzydłowski KJ. Dental plaque as a biofilm - a risk in oral cavity and methods to prevent [in Polish]. Postepy Hig Med Dosw (Online). 2015;69:1140-1148. doi:10.5604/17322693.1173925

32. Costerton JW, Stewart PS, Greenberg EP. Bacterial biofilms: A common cause of persistent infections. Science. 1999;284(5418):1318-1322. doi:10.1126/science.284.5418.1318

33. Zehnder M. Root canal irrigants. J Endod. 2006;32(5):389-398. doi:10.1016/j.joen.2005.09.014

34. Hecker S, Hiller KA, Galler KM, Erb S, Mader T, Schmalz G. Establishment of an optimized ex vivo system for artificial root canal infection evaluated by use of sodium hypochlorite and the photodynamic therapy. Int Endod J. 2013;46(5):449-457. doi:10.1111/iej.12010

35. Stojicic $S$, Amorim $H$, Shen $Y$, Haapasalo M. Ex vivo killing of Enterococcus faecalis and mixed plaque bacteria in planktonic and biofilm culture by modified photoactivated disinfection. Int Endod J. 2013;46(7):649659. doi:10.1111/iej.12041

36. Schiffner U, Cachovan G, Bastian J, Sculean A, Eick S. In vitro activity of photoactivated disinfection using a diode laser in infected root canals. Acta Odontol Scand. 2014;72(8):673-680. doi:10.3109/00016357.2014.898087

37. Bhatti M, MacRobert A, Meghji S, Henderson B, Wilson M. Effect of dosimetric and physiological factors on the lethal photosensitization of Porphyromonas gingivalis in vitro. Photochem Photobiol. 1997;65(6):10261031. doi:10.1111/j.1751-1097.1997.tb07964.x

38. Garcez AS, Núñez SC, Lage-Marques JL, Cardoso Jorge AO, Ribeiro MS. Efficiency of $\mathrm{NaOCl}$ and laser-assisted photosensitization on the reduction of Enterococcus faecalis in vitro. Oral Surg Oral Med Oral Pathol Oral Radiol Endod. 2006;102(4):e93-e98. doi:10.1016/j.tripleo.2006.02.015

39. Yildirim C, Karaarslan ES, Ozsevik S, Zer Y, Sari T, Usumez A. Antimicrobial efficiency of photodynamic therapy with different irradiation durations. Eur J Dent. 2013;7(4):469-473. doi:10.4103/1305-7456.120677

40. Rios A, He J, Glickman GN, Spears R, Schneiderman ED, Honeyman AL. Evaluation of photodynamic therapy using a light-emitting diode lamp against Enterococcus faecalis in extracted human teeth. J Endod. 2011;37(6):856-859. doi:10.1016/j.joen.2011.03.014

41. Lim Z, Cheng JL, Lim TW, et al. Light activated disinfection: An alternative endodontic disinfection strategy. Aust Dent J. 2009;54(2):108-114. doi:10.1111/j.1834-7819.2009.01102.x

42. $\mathrm{Ng} \mathrm{R}$, Singh F, Papamanou DA, et al. Endodontic photodynamic therapy ex vivo. J Endod. 2011;37(2):217-222. doi:10.1016/j.joen.2010.10.008

43. Singh S, Nagpal R, Manuja N, Tyagi SP. Photodynamic therapy: An adjunct to conventional root canal disinfection strategies. Aust Endod J. 2015;41(2):54-71. doi:10.1111/aej.12088

44. Zhang T, Wang L, Chen Q, Chen C. Cytotoxic potential of silver nanoparticles. Yonsei Med J. 2014;55(2):283-291. doi:10.3349/ymj.2014.55.2.283

45. Bhardwaj SB, Mehta M, Gauba K. Nanotechnology: Role in dental biofilms. Indian J Dent Res. 2009;20(4):511-513. doi:10.4103/0970-9290.59440

46. Lotfi M, Vosoughhosseini S, Ranjkesh B, Khani S, Saghiri M, Zand V. Antimicrobial efficacy of nanosilver, sodium hypochlorite and chlorhexidine gluconate against Enterococcus faecalis. Afr J Biotechnol. 2011;10(35):6799-6803.

47. Yin $\mathrm{R}$, Agrawal $\mathrm{T}$, Khan U, et al. Antimicrobial photodynamic inactivation in nanomedicine: Small light strides against bad bugs. Nanomedicine (Lond). 2015;10(15):2379-2404. doi:10.2217/nnm.15.67

48. George S, Kishen A. Augmenting the antibiofilm efficacy of advanced noninvasive light activated disinfection with emulsified oxidizer and oxygen carrier. J Endod. 2008;34(9):1119-1123. doi:10.1016/j.joen.2008.06.019

49. Shrestha A, Kishen A. Antibiofilm efficacy of photosensitizerfunctionalized bioactive nanoparticles on multispecies biofilm. J Endod. 2014;40(10):1604-1610. doi:10.1016/j.joen.2014.03.009 